\begin{tabular}{lcl|l}
\hline Bentham OPEN & The Open Neurology Journal & $\begin{array}{c}\text { The Open } \\
\text { Neurology } \\
\text { lournal } \\
\text { CrossMark }\end{array}$ \\
\hline
\end{tabular}

RESEARCH ARTICLE

\title{
Relationship Between Patients with Clinical Auditory Neuropathy Spectrum Disorder and Mutations in Gjb2 Gene
}

\author{
Guilherme M. de Carvalho, ${ }^{1, *}$, Priscila Z. Ramos ${ }^{2}$, Arthur M. Castilho ${ }^{1}$, Alexandre C. Guimarães ${ }^{1}$ \\ and Edi L. Sartorato ${ }^{3}$

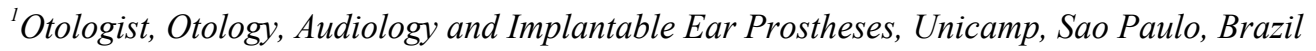 \\ ${ }^{2}$ Human Molecular Genetics Laboratory, Molecular Biology and Genetic Engineering Center, CBMEG, Unicamp, Sao \\ Paulo, Brazil \\ ${ }^{3}$ Molecular Biology and Genetic Engineering Center, CBMEG, Unicamp, Sao Paulo, Brazil
}

Received: August 22, 2015

Revised: September 20, 2015

Accepted: October 22, 2015

\section{Abstract:}

The auditory neuropathy is a condition which there is a dyssynchrony in the nerve conduction of the auditory nerve fibers. There is no evidence about the relationship between patients with clinical auditory neuropathy spectrum disorder and mutations in GJB2 gene. There are only two studies about this topic in the medical literature. Connexin 26 (GJB2 gene) mutations are common causes of genetic deafness in many populations and we also being reported in subjects with auditory neuropathy.

\section{Objective:}

To analyze the pattern of clinical relationship between patients with clinical diagnosis with auditory neuropathy spectrum disorder and GJB2 gene.

\section{Patients and Methods:}

Study Design - Retrospective analysis and genetic evaluation. Setting - Tertiary referral center. Subjects - 40 patients with Auditory Neuropathy Spectrum Disorder. Intervention - Clinical information and genetic evaluation (GJB2 gene) were analyzed.

\section{Results:}

Biallelic mutations that accounted for hearing loss (HL) were found in three patients, both with c.35delG mutation in homozygous state. The splice site mutation IVS1+1G $>$ A was detected in heterozygous state in one individual. However, since the second mutant allele was not identified, it was not possible to establish its correlation with the phenotype.

\section{Conclusion:}

Mutations in GJB2 gene mutations were found in 7.5\% of the patients with ANSD. We found no relationship between patients with clinical auditory neuropathy spectrum disorder and mutations in GJB2 gene $(p>0.05)$.

Keywords: GJB2, Auditory neuropathy spectrum disorder, Evoked auditory brainstem response, Hearing loss, Otoacoustic emissions.

\section{INTRODUCTION}

Auditory neuropathy spectrum disorder (ANSD) is the synchrony loss related to the auditory pathway, resulting in a

\footnotetext{
* Address correspondence to this author at the Otology, Audiology and Implantable Ear Prostheses, Ear, Nose, Throat and Head \& Neck Surgery Department, P.O. BOX 6111, Postal Code: 13081-970, São Paulo, Brazil; Tel: +55 19 35217523; Fax: +55 19 35217563; E-mail: guimachadocarvalho@gmail.com
} 
deficitary nerve conduction in the auditory nerve fibers, probably secondary to a demyelination of the $8^{\text {th }}$ cranial nerve. ANSD can affect individuals of any age, from newborns to adults, and can be caused by a variety of environmental or others clinical conditions (such as anoxia and hyperbilirubinemia) and genetic factors. The prevalence of ANSD in children with severe or profound hearing loss is estimated at $13.4 \%[1-3]$.

ANSD is characterized by outer hair cells (OHCs) function preservation associated with lack of response in the brainstem evoked response audiometry (ABR) test. The outer hair cells functionality is demonstrated by the positive response of otoacoustic emissions (OAEs) and/or cochlear microphonic (CM) detection, while no synchronous neural activity is detected in the ABR test $[4,5]$.

It is believed that there are several topographical transmission failure sites in the auditory action potential, such as damage at the tectorial membrane and internal hair cell; changes in neurotransmitter release in the synapses between the inner hair cell and spiral ganglion neurons fibers; changes in electrical transmission in cochlear nerve fibers or axons or problems related to cochlear nerve myelination $[1,2,6]$.

Clinically, the patients with ANSD can present with many degrees of unilateral or bilateral hearing loss (symmetric or not). The speech discrimination is low and incompatible with audiometric thresholds. Patients with ANSD may have fluctuating hearing levels; sometimes, the individual appears to have normal hearing and its behavior resembles an individual with auditory disabilities [7].

The presence of OAEs with absent or abnormal ABR supports the clinical diagnosis. The CM may be present and the acoustic reflexes may be absent. There may be some correlation with pathologies that occur with peripheral neuropathy such as Guillain-Barré syndrome and Charcot-Marie-Tooth [8,9]. The therapeutic intervention in patients with auditory neuropathy needs to be made by hearing stimulation and speech therapy, and the cochlear implants or hearign aids could be a great assistance and must be performed as soon as possible [10].

In the last decade, the genes identification responsible for ANSD had great contribution for the diagnosis and better understanding of the mechanisms involved in this disorder $[5,6,11]$.

Four loci responsible for nonsyndromic ANSD were mapped to date: DFNB9 (OTOF gene) and DFNB59 (PJVK gene) for autosomal recessive ANSD; AUNA1 (DIAPH3 gene) for autosomal dominant ANSD; and AUNX1 for Xlinked ANSD. In addition, mutations in GJB2 gene and mitochondrial 12S rRNA gene have been also related to this disorder $[4,7-10,12]$.

Most genetic studies on the etiology of ANSD exclude cases that may have originated in GJB2 gene, environmental or host factors, in order to be more effective in the search for new genes or genetic factors that may explain this pathology.

There are only two studies that reported the relationship of the GJB2 gene with ANSD. The first one described five individuals with preserved OAEs, among 777 unrelated subjects attending schools for the deaf or receiving special services for their moderate to profound HL, carrying mutations in the GJB2 gene, either in homozygous state (c.35del $\mathrm{G} / \mathrm{c} .35 \mathrm{delG}$ or $\mathrm{p} . \mathrm{W} 77 \mathrm{X} / \mathrm{p} . \mathrm{W} 77 \mathrm{X}$ ) or in compound heterozygous state (c.35delG/c.360delGAG, c.35delG/p.V95M and p.M34T/p.V84M) [13].

However, the clinical diagnosis of ANSD was confirmed only in one case. So, this Asian study highlighted that 6.5 $\%$ of patients with clinical diagnostic of ANSD (OEA +/ABR -) feature homozigose compound heterozygous for the GJB2 (c.35delG/c.35delG or p.W77X/p.W77X/c.35delG/c.360 delGAG, c.35delG/p.V95M and p.M34T/p.V84M) [13].

The second paper, a case series, about GJB2 gene and ANSD reported two children homozygous for c. $35 \mathrm{delG}$ and one heterozygous for p.M34T, showing moderate to profound hearing loss and preservation of OAEs. However, further investigation revealed that only one child homozygous for c.35delG could have ANSD [14].

Despite mutations in GJB2 gene are clearly related to unilateral non syndromic hearing loss and is the most common genetic finding in hearing loss diseases, the relationship with Auditory Neuropathy Spectrum Disorder (ANSD) is still unclear [13 - 16].

In this paper we conducted a literature review on the mutations in GJB2 gene in patients with ANSD, and studied this relationship in our population. Only few articles studied this relationship and more data about this topic can help another studies and protocols of the investigation and development of knowledge of ANSD. 
This research article is important because it is the first Brazilian and Latin American review on this topic, it shows the most frequent causes ANSD, and the peculiarities of ANSD and this relationship with mutations in GJB2 gene.

We believe that these findings are of great importance to all professionals who work with patients with auditory neuropathy, such as pediatrician, otolaryngologists, audiologists, genetics and researches teams.

The underlying causes of ANSD are highly questionable and uncertain; therefore the study of GJB2 involvement in patients with ANSD can help to guide new studies, new discoveries and the interface of these genetic alterations with different clinical phenotypes of deafness.

This paper aims to study the relationship between the clinical diagnosis of auditory neuropathy spectrum disorder and mutations in the GJB2 gene.

\section{METHODS}

We conducted a retrospective observational study through analysis of medical records of patients diagnosed with bilateral hearing loss, with suspected ANSD, accompanied in the auditory health care service of a tertiary care university hospital.

The analyzed variables were age, gender, age of onset of the hearing loss (congenital, childhood, adolescent or adult), past history, previous pregnancies, perinatal and genetic data and electrophysiological test results (ABR, transient and distortion product otoacoustic emissions (OAE), and search of cochlear microphonics (CMs)).

The age group was defined as reported in the medical records of the early onset of symptoms, as follows: congenital (up to 1 year old), childhood (between 1 and 10 years old), adolescent (between 11 and 18 years of life) or adult (over 18 years of life).

The clinical diagnosis of ANSD was established as follows: absent or abnormal ABR with preservation of otoacoustic emissions and/or CMs. All patients had no acoustic reflex and the presence of the cochlear nerve was assessed by nuclear magnetic resonance (MRI) and computed tomography (CT).

\section{Molecular Study}

Genomic DNA was extracted from patient peripheral venous blood according to standard protocols. GJB2 mutations were screened by direct sequencing of the gene coding region and the exon 1 and flanking splice donor site [17 - 19].

\section{Inclusion Criteria}

Inclusion criteria were: sensorineural hearing loss, normal otoscopy, absence of middle ear disease, absence of acoustic reflex, presence of transient and/or distortion product OAEs, absence or abnormality in ABR waves and imaging (MRI/CT) showing the presence of the cochlear nerve and excluding retrocochlear disturbances.

All patients who did not complete these criteria were excluded from the study.

\section{Audiological Evaluation}

Audiological tests were performed including impedanciometry, speech and pure tone audiometry. The tests were performed using an audiometer AC30-SD25, calibrated according to ISO 389 standards/ 64 .

For ABR, which were repeated at least two times, we used the device AT-235 (Interacoustics).

\section{Statistical Analysis}

The data were analyzed using descriptive analysis, with production of means, medians and standard deviation tabs.

Chi-Square was used to compare the groups of our sample. Because of the small size of some of the variables analyzed Fisher's Exact test was also used to check the correlation between the groups.

The confidence Interval was of $95 \%$, and $p$-value $<0.05$ was considered significant.

\section{Ethical Considerations}

This study was previously approved by the Research Ethics Committee of the Faculty of Medical Sciences of the University of Campinas (Report number 396/2006). 


\section{RESULTS}

According to the criteria established in the methodology, 40 patients with ANSD were selected after the review of the medical records.

Most patients, $75 \%$, had onset of symptoms in the first year of life (30 congenital; 3 child; 4 adolescence; 2 adult) and $65 \%$ were male (26 male; 14 female). In 23 subjects, $57.5 \%$ of the cases, no genetic or environmental factor that could be related to the etiology of the disease were observed.

We observed that ANSD could be associated with hyperbilirubinemia in only two cases, i.e., a neonatal jaundice with phototherapy and kernicterus. Three cases had family history of sensorineural deafness. In $25 \%$ of cases the patients were premature (mean of 32,8 weeks (range 28 to 36 days) - median of 28 weeks), and in $25 \%$ of cases. (Mean of 20,7 days (range 5 to 42 days) - median of 27,5 days) they were hospitalized in the neonatal intensive care unit (NICU) .

Regarding infectious diseases, only one case of meningitis during the neonatal ICU was reported, one case of aspiration pneumonia at three months of life with need of hospital treatment and one case of gestational toxoplasmosis (case with also bilateral enlarged vestibular aqueduct in radiologic evaluation).

Syndromic features were observed in only one case (Charge syndrome). Regarding systemic neuromuscular diseases, axial ascending muscular atrophy was observed in only one subject. No others known causes of peripheral neuropathies were present. One of the patients (adult) had arterial hypertension and diabetes without other relevant risk factors for hearing loss.

ABR was abnormal or absent in all cases. The classic situation in which OAEs are present with absent ABR occurred in only $47.5 \%$ of cases; the presence of CM was also noted in three of these patients $(\mathrm{OEA}+\mathrm{ABR}-\mathrm{CM}+)$. The remaining patients (52.5\%) showed absent OAE and ABR with the presence of CMs.

Radiologic abnormalities were identified in three cases, including enlargement of vestibular aqueduct bilaterally (OAE-, ABR-, CM + and gestational toxoplasmosis), a cyst arachnoid in left cerebellar point angle (OAE-, ABR-, CM + ) and signs of involvement of kernicterus (OAE +, ABR -, CM-). See more details at Table 1.

Table 1. Patients' distribution according to gender, age of onset, audiological evaluation and genetic background.

\begin{tabular}{|c|c|c|c|c|c|c|c|}
\hline ANSD & Sex & Age & OAE & ABR & $\mathbf{C M}$ & GJB2 Genotype & Past History \\
\hline \begin{tabular}{|l|l|l}
1 & \\
\end{tabular} & $\mathrm{~F}$ & Childhood & + & No response & - & $\mathrm{wt} / \mathrm{wt}$ & None \\
\hline 2 & M & Congenital & + & No response & + & wt/wt & Preterm baby ( $35 \mathrm{wks}) /$ neonatal unity care for 10 days \\
\hline 3 & $\mathrm{M}$ & Congenital & + & No response & - & wt/wt & None \\
\hline 4 & $\mathrm{M}$ & Adolescent & + & No response & - & $\mathrm{wt} / \mathrm{wt}$ & None \\
\hline 5 & $\mathrm{M}$ & Congenital & + & No response & - & $\mathrm{wt} / \mathrm{wt}$ & None \\
\hline 6 & $\mathrm{~F}$ & Congenital & + & No response & + & $\mathrm{wt} / \mathrm{wt}$ & Preterm baby (36 wks) \\
\hline 7 & $\mathrm{M}$ & Adult & + & No response & - & $\mathrm{IVS} 1+\mathrm{G}>\mathrm{A} / \mathrm{wt}$ & None \\
\hline 8 & $\mathrm{~F}$ & Congenital & + & No response & - & $\mathrm{wt} / \mathrm{wt}$ & None \\
\hline 9 & $\mathrm{~F}$ & Childhood & + & No response & - & wt/wt & None \\
\hline 10 & $\mathrm{M}$ & Congenital & + & No response & - & $\mathrm{wt} / \mathrm{wt}$ & None \\
\hline 11 & $\mathrm{M}$ & Congenital & + & No response & + & $\mathrm{wt} / \mathrm{wt}$ & Brother with SNHL \\
\hline 12 & $\mathrm{M}$ & Congenital & + & No response & - & $\mathrm{wt} / \mathrm{wt}$ & Kernicterus \\
\hline 13 & $\bar{F}$ & Congenital & + & No response & - & $\mathrm{wt} / \mathrm{wt}$ & $\begin{array}{c}\text { Preterm baby (29 wks), neonatal unity care for } 35 \text { days, neonatal } \\
\text { CRA }\end{array}$ \\
\hline 14 & $\mathrm{M}$ & Adult & + & No response & - & $\mathrm{wt} / \mathrm{wt}$ & None \\
\hline 15 & $\mathrm{~F}$ & Congenital & + & No response & - & wt/wt & $\begin{array}{c}\text { Neonatal jaundice, preterm baby (36 wks), neonatal unity care } \\
\text { for } 26 \text { days }\end{array}$ \\
\hline 16 & $\mathrm{~F}$ & Congenital & + & No response & - & $\mathrm{wt} / \mathrm{wt}$ & Axial ascending muscular atrophy \\
\hline 17 & $\mathrm{M}$ & Adolescent & + & No response & - & wt/wt & None \\
\hline 18 & $\mathrm{M}$ & Congenital & + & No response & - & c. $35 \mathrm{delG} / \mathrm{c} .35 \mathrm{delG}$ & None \\
\hline 19 & $\mathrm{M}$ & Congenital & + & No response & - & c.35delG/c.35delG & None \\
\hline 20 & $\mathrm{~F}$ & Congenital & - & No response & + & $\mathrm{wt} / \mathrm{wt}$ & None \\
\hline 21 & $\mathrm{M}$ & Congenital & - & No response & + & wt/wt & None \\
\hline 22 & $\mathrm{~F}$ & Congenital & - & No response & + & $\mathrm{wt} / \mathrm{wt}$ & None \\
\hline 23 & $\mathrm{M}$ & Congenital & - & No response & + & $\mathrm{wt} / \mathrm{wt}$ & None \\
\hline 24 & M & Congenital & - & No response & + & wt/wt & Charge syndrome \\
\hline 25 & $\mathrm{M}$ & Congenital & - & No response & + & $\mathrm{wt} / \mathrm{wt}$ & None \\
\hline 26 & $\mathrm{M}$ & Congenital & - & No response & + & $\mathrm{wt} / \mathrm{wt}$ & Preterm baby ( $27 \mathrm{wks})$, neonatal unity care for 30 days \\
\hline
\end{tabular}




\begin{tabular}{|c|c|c|c|c|c|c|c|}
\hline ANSD & Sex & Age & OAE & $\mathbf{A B R}$ & $\mathbf{C M}$ & GJB2 Genotype & Past History \\
\hline 27 & $\mathrm{M}$ & Congenital & - & No response & + & $\mathrm{wt} / \mathrm{wt}$ & $\begin{array}{c}\text { Preterm baby ( } 28 \text { wks), neonatal unity care for } 42 \text { days, } \\
\text { meningitis }\end{array}$ \\
\hline 28 & $\mathrm{M}$ & Congenital & - & No response & + & $\mathrm{wt} / \mathrm{wt}$ & Preterm baby ( $32 \mathrm{wks})$, neonatal unity care for 14 days \\
\hline 29 & $\mathrm{M}$ & Congenital & - & No response & + & $\mathrm{wt} / \mathrm{wt}$ & Neonatal unity care for 10 days \\
\hline 30 & $\mathrm{M}$ & Congenital & - & No response & + & $\mathrm{wt} / \mathrm{wt}$ & None \\
\hline 31 & $\mathrm{~F}$ & Congenital & - & No response & + & $\mathrm{wt} / \mathrm{wt}$ & Gestational toxoplasmosis \\
\hline 32 & $\mathrm{~F}$ & Congenital & - & No response & + & $\mathrm{wt} / \mathrm{wt}$ & aspiration pneumonia 3 months old \\
\hline 33 & $\overline{\mathrm{M}}$ & Congenital & - & No response & + & c.35delG/c.35delG & Preterm baby ( $35 \mathrm{wks})$, neonatal unity care for 05 days \\
\hline 34 & $\mathrm{M}$ & Congenital & - & No response & + & $\mathrm{wt} / \mathrm{wt}$ & Preterm baby ( $35 \mathrm{wks})$, neonatal unity care for 19 days \\
\hline 35 & $\mathrm{~F}$ & Adolescent & - & No response & + & $\mathrm{wt} / \mathrm{wt}$ & Systemic arterial hypertension, diabetes mellitus \\
\hline 36 & $\mathrm{M}$ & Congenital & - & No response & + & $\mathrm{wt} / \mathrm{wt}$ & Brother with SNHL \\
\hline 37 & $\mathrm{~F}$ & Adolescent & - & No response & + & $\mathrm{wt} / \mathrm{wt}$ & None \\
\hline 38 & M & Congenital & - & No response & + & $\mathrm{wt} / \mathrm{wt}$ & Preterm baby ( $35 \mathrm{wks})$, neonatal unity care for 16 days \\
\hline 39 & $\mathrm{~F}$ & Congenital & - & No response & + & $\mathrm{wt} / \mathrm{wt}$ & None \\
\hline 40 & $\mathrm{M}$ & Childhood & - & No response & + & $\mathrm{wt} / \mathrm{wt}$ & None \\
\hline
\end{tabular}

Ps.: M: male; F: female; +: positive; -: negative; N/A: not available; wt: wild type.

\section{Genetic Testing}

Sequence analysis of GJB2 gene was performed in all 40 patients with clinical diagnosis of ANSD. Pathogenic variants in the connexin 26 gene were identified in four subjects. Biallelic mutations that accounted for hearing loss (HL) were found in three patients, all of them with c.35delG mutation in homozygous state. The splice site mutation IVS1+1G $>$ A was detected in heterozygous state in one individual. However, since the second mutant allele was not identified, it was not possible to establish its correlation with the phenotype. See more details at Table 2.

Table 2. Patients details with pathogenic variants in the connexin 26 gene.

\begin{tabular}{|c|c|c|c|c|}
\hline ANSD & Case 18 & Case 19 & Case 33 & Case 7 * \\
\hline Gender & Male & Male & Male & Male \\
\hline Age (at diagnosis) & Congenital & Congenital & Congenital & Adult \\
\hline $\mathrm{OAE}$ & \pm & + & - & \pm \\
\hline $\mathrm{ABR}$ & absent & absent & absent & absent \\
\hline $\mathrm{CM}$ & - & - & + & - \\
\hline GJB2 Genotype & c.35delG/c.35delG & c.35delG/c.35delG & c.35delG/c.35delG & $\mathrm{IVS} 1+\mathrm{G}>\mathrm{A} / \mathrm{wt}$ \\
\hline Pure Tone Thresholds & $50-70 \mathrm{~dB}$ & $60-80 \mathrm{~dB}$ & $80-100 \mathrm{~dB}$ & $40-70 \mathrm{~dB}$ \\
\hline IRF & $68 \%$ & NA & $50 \%$ & $72 \%$ \\
\hline LRF & $65 \mathrm{~dB}$ & $70 \mathrm{~dB}$ & $60 \mathrm{~dB}$ & $40 \mathrm{~dB}$ \\
\hline Past History & None & None & $\begin{array}{l}\text { Preterm baby ( } 35 \text { wks) NICU } \\
(5 \mathrm{~d})\end{array}$ & None \\
\hline CT/MNR & Normal & Normal & Normal & Normal \\
\hline Treatment & $\mathrm{CI}+\mathrm{HA}+$ speech therapy & $\mathrm{CI}+\mathrm{HA}+$ speech therapy & $\mathrm{CI}+\mathrm{HA}+$ speech therapy & HA + speech therapy \\
\hline Ps. & & $\begin{array}{l}\text { detects plate and barrel in } \\
\text { behavioral audiometry with hearing } \\
\text { aids and / a / \& / u / }\end{array}$ & & $\begin{array}{c}\text { Understanding speech } \\
\text { difficulty; PTA oscillations; } \\
\text { Some audiogram similar to } \\
\text { conductive HL }\end{array}$ \\
\hline
\end{tabular}

Ps.: M: male; F: female; +: positive; -: negative; N/A: not available; wt: wild type; CI: cochlear implant; HA: hearing aids. PTA: pure tone audiometry; HL: hearing loss. NICU: neonatal unity care unity.

All the variables with GJB2 gene' homozygous were matched (Chi-Square and Fischer-t-Test) and we did not found any relevant correlation.

We found correlation between the mutation of $G J B 2$ gene' homozygous only with moderate $(p=0,03)$ and severe $(p=0,02)$ hearing loss associated with the presence of $\mathrm{CM}$, however the Fischer-t-Test did not confirm this relationship.

The variables analyzed about the relationship with GJB2 gene were: neonatal care unit, past history, gender, prematurity, jaundice, other peripheral neuropathies, infectious disease, radiologic abnormalities, syndromic comorbidities, OEA+ABR-, OEA+ABR-CM+, age, presence and absence of OEA, presence and absence $\mathrm{CM}$, hearing loss (mild to profound).

The relationships between hearing loss and the presence of $\mathrm{CM}$ and hearing loss with OEA+ABR- or OEA-ABR$\mathrm{CM}+$ were also evaluated, with no significant findings. See more details at Table 3.

\section{DISCUSSION}

ANSD, unknown until recently, is a condition that has been more studied in the last decade, and 
electrophysiological tests for hearing are essential tools for proper diagnosis and knowledge of its pathophysiology. The diagnosis is primarily based on changes in ABR associated with normal OAEs [2].

OAEs are used to evaluate the function of outer hair cells and represent preneural phenomenon related to mechanical processes in the cochlea. The presence of OAE depends on an intact auditory system. They check the organ of Corti functioning and the efferent auditory system (OHCs) [1, 20].

Table 3. Audiometric thresholds of all subjects [27].

\begin{tabular}{|c|c|c|c|c|c|}
\hline PTA & Total (n) & OEA + BERA - & OEA - BERA - MC + & OEA + BERA - MC+ & MC + \\
\hline Low & 5 & 2 & 3 & 6 & 0 \\
\hline Moderated & 15 & 9 & 6 & 8 & 6 \\
\hline Severe & 11 & 5 & 4 & 9 \\
\hline Profound & 9 & 19 & 21 & 2 \\
\hline Total (n) & 40 & 6 & 24 \\
\hline
\end{tabular}

$\mathrm{CM}$ is another way to verify the cochlear integrity and functioning. It is an alternating current potential that occurs during the sound stimulus and reflects the movement of the basilar membrane [20]. CM is a preneural electrical activity, i.e., it occurs before hair cell synapses in the auditory nerve, and thus appears before the wave I in the ABR record [21].

Cochlear microphonic was present in 60\% (24 cases) of the patients, which denotes some degree of cochlear integrity and inner hair cells (IHCs) functioning in these individuals. However, it should be noted that 52,5\% (21 cases) of patients had absent transient OAEs, which does not favor the diagnosis. In our study, a large portion of the subjects included had hearing loss onset at congenital age (75\%).

ABR was absent or abnormal in all cases. ANSD classically presents with impaired speech discrimination. In individuals with congenital hearing loss, obviously that deficit would result in an impaired speech development [2, 20]. The study showed that $51 \%$ of the patients had poor speech development, with great difficulty understanding speech, other $26.7 \%$ had speech deemed modified (dislalia), although intelligible (reasonable) and 22.3\% had good speech without compromising the understanding.

In our cohort, $42.5 \%$ (17 cases) of patients had environmental factors or other clinical conditions that may be related to ANSD, such as neonatal ICU, prematurity, family history of deafness, among others. Many recent studies have aimed to identify the possible mechanisms responsible for auditory neuropathy, particularly the involvement of genetic factors $[1,2,22]$.

Three out of the 40 patients with clinical diagnosis of ANSD were homozygous for c. 35 delG mutation. Mutations in the connexin 26 gene are frequent in many populations, accounting for up to $50 \%$ of all ANSD cases. Interestingly, two different studies also reported the finding of ANSD in individuals with HL carrying GJB2 mutations [13, 14].

There is no scientific evidence to support the real relationship between ANSD and mutations in the GJB2 gene. This gene is expressed in the cochlea non sensory cells (support cells) and encodes the connexin 26 protein, which is associated with the cellular communication (gap junctions), forming channels that mediate passage of small ions and molecules across cell membranes, allowing for example, the recycling of potassium ions in the cochlear fluids [13, 14, $23,24]$.

Mutations in this gene can alter the function of connexin 26 to cause deficiency in the flow of potassium ions, which can lead to cell death and consequently deafness since high potassium levels may affect the function and survival of cells necessary to support hearing [13, 14, 23, 24].

It is possible that OAE observed in patients with ANSD represents residual activity of a few outer hair cells remained alive in the apical part of the cochlea, and thus the hearing loss observed in these cases would not fit the diagnosis of ANSD [24].

It is currently known that the connexin 26 deficiency disrupts the inner ear ion homeostasis, which leads to a local extracellular accumulation of potassium and cell death [25].

Conversely, Matsunaga's recent reports also highlights that mutations in connexin 26 gene may cause impairment of inner hair cells and nerve endings beneath the hair cells and be responsible for nonsyndromic recessive ANSD [26]. Thereby, further studies are necessary to clarify the link between GJB2 mutations and ANSD [20].

The identification of genetic alterations responsible for ANSD may contribute for a better understanding of the molecular basis and pathophysiological mechanisms involved in different hearing loss phenotypes. The use of new 
molecular tools allowing a faster and more effective diagnosis is of great importance for the prognosis and also for the patients' treatment.

Genetic testing, combined with clinical and audiological exams, allows an accurate diagnosis, as well as the development of more specific treatments and genetic counseling of patients and/or families [16].

There is no scientific evidence to support the real relationship between ANSD and mutations in the GJB2 gene. This gene is expressed in the cochlea non sensory cells (support cells) and encodes the connexin 26 protein, which is associated with the cellular communication (gap junctions), forming channels that mediate passage of small ions and molecules across cell membranes, allowing for example, the recycling of potassium ions in the cochlear fluids [13 - 16].

In this paper we conducted a literature review on the mutations in GJB2 gene in patients with ANSD, and studied this relationship in our population. Only few articles studied this relationship and more data about this topic can help another studies and protocols of the investigation and development of knowledge of ANSD.

This research article is important because it is the first Brazilian and Latin American review on this topic, it shows the most frequent causes ANSD, and the peculiarities of ANSD and this relationship with mutations in GJB2 gene.

We believe that these findings are of great importance to all professionals who work with patients with auditory neuropathy, such as pediatrician, otolaryngologists, audiologists, genetics and researches teams.

The underlying causes of ANSD are highly questionable and uncertain; therefore the study of GJB2 involvement in patients with ANSD can help guide new studies, new discoveries and the interface of these genetic alterations with different clinical phenotypes of deafness.

The diagnosis of ANSD should be considered in patients with bilateral hearing loss initiated until adolescence. Studies should be performed to determine the role of perinatal and genetic conditions in the origin of the disease.

The knowledge of clinical features of ANSD, as specified in the above data, allows us to presume that individuals diagnosed with hearing loss were more likely to present ANSD. The clinical skills improvement, combined with additional tests (genetic and audiological), allows large knowledge of ANSD's etiologies that are still being studied.

\section{CONCLUSION}

We found, a 7.5\% ratio of GJB2 gene mutations in patients with ANSD.

Evidences are lacking to show the actual relationship between ANSD and GJB2 gene.

\section{CONFLICT OF INTEREST}

The authors confirm that this article content has no conflict of interest.

\section{ACKNOWLEDGEMENTS}

We warmly thank our University, our Department, our patients and every person who support us to perform our work.

The present study, including the protocols for subject recruitment and assessment, the informed consent for participants, and the overall analysis plan were reviewed and approved by the Faculty of Medical Sciences $\square$ UNICAMP and the Center for Molecular Biology and Engineering (CBMEG), São Paulo, Brazil, by their doctoral programs and research ethics committees. The authors would also like to thank their University, their Department, their patients and every person who supported them in performing their research. This article is part of a doctoral project that is funded by CAPES (Higher Education Personnel Improvement Coordination, Ministry of Health, Brazil). The authors would like to thank to the Institutional Support from CNPq (National Council for Scientific and Technological Development).

UNICAMP Approval. The study, including the protocols for subject recruitment and assessment, the informed consent for participants, and the overall analysis plan were reviewed and approved by UNICAMP boards for the Faculdade de Ciências Médicas da Universidade Estadual de Campinas e do Centro de Biologia e Engenharia Molecular (CBMEG), São Paulo Brasil, through their doctoral programs and their research ethics committee.

\section{REFERENCES}


[2] Spinelli M, Fávero-Breuel ML, Silva CM. Auditory neuropathy: clinical, diagnostic and therapeutic aspects. Rev Bras Otorrinolaringol 2001; 6(67): 863-7.

[3] Sanyelbhaa Talaat H, Kabel AH, Samy H, Elbadry M. Prevalence of auditory neuropathy (AN) among infants and young children with severe to profound hearing loss. Int J Pediatr Otorhinolaryngol 2009; 73(7): 937-9.

[http://dx.doi.org/10.1016/j.ijporl.2009.03.009] [PMID: 19409623]

[4] Yasunaga S, Grati M, Cohen-Salmon M, et al. A mutation in OTOF, encoding otoferlin, a FER-1-like protein, causes DFNB9, a nonsyndromic form of deafness. Nat Genet 1999; 21(4): 363-9. [http://dx.doi.org/10.1038/7693] [PMID: 10192385]

[5] Rodríguez-Ballesteros M, Reynoso R, Olarte M, et al. A multicenter study on the prevalence and spectrum of mutations in the otoferlin gene (OTOF) in subjects with nonsyndromic hearing impairment and auditory neuropathy. Hum Mutat 2008; 29(6): 823-31. [http://dx.doi.org/10.1002/humu.20708] [PMID: 18381613]

[6] Romanos J, Kimura L, Fávero ML, et al. Novel OTOF mutations in Brazilian patients with auditory neuropathy. J Hum Genet 2009; 54(7): 382-5.

[http://dx.doi.org/10.1038/jhg.2009.45] [PMID: 19461658]

[7] Delmaghani S, del Castillo FJ, Michel V, et al. Mutations in the gene encoding pejvakin, a newly identified protein of the afferent auditory pathway, cause DFNB59 auditory neuropathy. Nat Genet 2006; 38(7): 770-8. [http://dx.doi.org/10.1038/ng1829] [PMID: 16804542]

[8] Schoen CJ, Emery SB, Thorne MC, et al. Increased activity of Diaphanous homolog 3 (DIAPH3)/diaphanous causes hearing defects in humans with auditory neuropathy and in Drosophila. Proc Natl Acad Sci USA 2010; 107(30): 13396-401.

[http://dx.doi.org/10.1073/pnas.1003027107] [PMID: 20624953]

[9] Wang QJ, Li QZ, Rao SQ, et al. AUNX1, a novel locus responsible for X linked recessive auditory and peripheral neuropathy, maps to Xq23-27.3. J Med Genet 2006; 43(7): e33. [http://dx.doi.org/10.1136/jmg.2005.037929] [PMID: 16816020]

[10] Chaïb H, Place C, Salem N, et al. A gene responsible for a sensorineural nonsyndromic recessive deafness maps to chromosome 2p22-23. Hum Mol Genet 1996; 5(1): 155-8. [http://dx.doi.org/10.1093/hmg/5.1.155] [PMID: 8789454]

[11] Manchaiah VK, Zhao F, Danesh AA, Duprey R. The genetic basis of auditory neuropathy spectrum disorder (ANSD). Int J Pediatr Otorhinolaryngol 2011; 75(2): 151-8.

[http://dx.doi.org/10.1016/j.ijporl.2010.11.023] [PMID: 21176974]

[12] Kim TB, Isaacson B, Sivakumaran TA, Starr A, Keats BJ, Lesperance MM. A gene responsible for autosomal dominant auditory neuropathy (AUNA1) maps to 13q14-21. J Med Genet 2004; 41(11): 872-6. [http://dx.doi.org/10.1136/jmg.2004.020628] [PMID: 15520414]

[13] Cheng X, Li L, Brashears S, et al. Connexin 26 variants and auditory neuropathy/dys-synchrony among children in schools for the deaf. Am J Med Genet A 2005; 139(1): 13-8.

[http://dx.doi.org/10.1002/ajmg.a.30929] [PMID: 16222667]

[14] Santarelli R, Cama E, Scimemi P, Dal Monte E, Genovese E, Arslan E. Audiological and electrocochleography findings in hearing-impaired children with connexin 26 mutations and otoacoustic emissions. Eur Arch Otorhinolaryngol 2008; 265(1): 43-51. [http://dx.doi.org/10.1007/s00405-007-0412-z] [PMID: 17701047]

[15] Denoyelle F, Weil D, Maw MA, et al. Prelingual deafness: high prevalence of a 30delG mutation in the connexin 26 gene. Hum Mol Genet 1997; 6(12): 2173-7. [http://dx.doi.org/10.1093/hmg/6.12.2173] [PMID: 9336442]

[16] Denoyelle F, Marlin S, Weil D, et al. Clinical features of the prevalent form of childhood deafness, DFNB1, due to a connexin-26 gene defect: implications for genetic counselling. Lancet 1999; 353(9161): 1298-303. [http://dx.doi.org/10.1016/S0140-6736(98)11071-1] [PMID: 10218527]

[17] Roush P, Frymark T, Venediktov R, Wang B. Audiologic management of auditory neuropathy spectrum disorder in children: a systematic review of the literature. Am J Audiol 2011; 20(2): 159-70. [http://dx.doi.org/10.1044/1059-0889(2011/10-0032)] [PMID: 21940978]

[18] Walton J, Gibson WP, Sanli H, Prelog K. Predicting cochlear implant outcomes in children with auditory neuropathy. Otol Neurotol 2008; 29(3): 302-9. [http://dx.doi.org/10.1097/MAO.0b013e318164d0f6] [PMID: 18317399]

[19] Shallop JK, Jin SH, Driscoll CL, Tibesar RJ. Characteristics of electrically evoked potentials in patients with auditory neurophaty/ auditory dys-synchrony. J Audiology 2005; 43: 22-7

[20] Penido RC, Isaac ML. Prevalence of auditory neuropathy spectrum disorder in an auditory health care service. Braz J Otorhinolaryngol 2013; 79(4): 429-33 [http://dx.doi.org/10.5935/1808-8694.20130077] [PMID: 23929141]

[21] Rance G, Beer DE, Cone-Wesson B, et al. Clinical findings for a group of infants and young children with auditory neuropathy. Ear Hear 1999; 20(3): 238-52. 
[http://dx.doi.org/10.1097/00003446-199906000-00006] [PMID: 10386850]

[22] Jeon JH, Bae MR, Song MH, Noh SH, Choi KH, Choi JY. Relationship between electrically evoked auditory brainstem response and auditory performance after cochlear implant in patients with auditory neuropathy spectrum disorder. Otol Neurotol 2013; 34(7): 1261-6. [http://dx.doi.org/10.1097/MAO.0b013e318291c632] [PMID: 23787967]

[23] Kelsell DP, Dunlop J, Stevens HP, et al. Connexin 26 mutations in hereditary non-syndromic sensorineural deafness. Nature 1997; 387(6628): 80-3.

[http://dx.doi.org/10.1038/387080a0] [PMID: 9139825]

[24] Del Castillo FJ, Del Castillo I. Genetics of isolated auditory neuropathies. Front Biosci (Landmark Ed) 2012; 17: 1251-65. [http://dx.doi.org/10.2741/3984] [PMID: 22201801]

[25] Cohen-Salmon M, Ott T, Michel V, et al. Targeted ablation of connexin26 in the inner ear epithelial gap junction network causes hearing impairment and cell death. Curr Biol 2002; 12(13): 1106-11. [http://dx.doi.org/10.1016/S0960-9822(02)00904-1] [PMID: 12121617]

[26] Matsunga T. Trends in genetic research in auditory neuropathy. In: Kaga K, Starr A, Eds. Neuropathies of the Auditory and Vestibular Eighth Cranial Nerves. Hong Kong: Springer 2009; pp. 43-51. [http://dx.doi.org/10.1007/978-4-431-09433-3_5]

[27] Goodman A. Reference zero levels for pure-tone audiometers. ASHA 1965; 7: 262-73. [http://dx.doi.org/10.1007/978-4-431-09433-3_5]

(C) de Carvalho et al.; Licensee Bentham Open.

This is an open access article licensed under the terms of the Creative Commons Attribution-Non-Commercial 4.0 International Public License (CC BY-NC 4.0) (https://creativecommons.org/licenses/by-nc/4.0/legalcode), which permits unrestricted, non-commercial use, distribution and reproduction in any medium, provided the work is properly cited. 